https://cssr.uitm.edu.my/2018/

5th International Conference on Science and Social Research

Le Meridien Kota Kinabalu Hotel, 5 - 6 December 2018

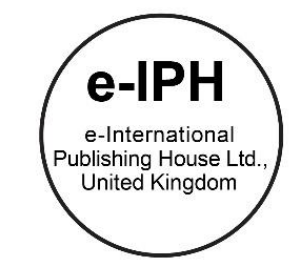

\title{
Healthy Lifestyles and Non-Communicable Diseases (NCD) among Urban Residents. Case Study: Sri Pahang Public Housing, Bangsar, Kuala Lumpur
}

\author{
Oliver Ling Hoon Leh, Nur Hidayah Shaharom, Marlyana Azyyati Marzukhi, Jamalunlaili Abdullah
}

Faculty of Architecture, Planning and Surveying, Environmental and Social Health Research Group, Universiti Teknologi MARA, 42300 Puncak Alam, Selangor, Malaysia

oliver3979@uitm.edu.my, hiedshaharom93@gmail.com, marlyana@uitm.edu.my, bota65@yahoo.com Tel: +6012-2380503

\begin{abstract}
Unhealthy lifestyle, especially the physical inactivity, can contribute to the increase in risk for non-communicable diseases (NCD). A study was carried out at Sri Pahang Public Housing area, Kuala Lumpur. The study aimed to investigate the healthy lifestyle and the relationship with the NCD. A questionnaire survey had been carried out to collect the data. From the statistical analysis, it is found that most of the respondents were less healthy regarding their lifestyle. Half of them did not carry out their exercise regularly. The physical inactive among respondents were significantly correlated to their health condition (NCD).
\end{abstract}

Keywords: Body mass index (BMI); exercise; physical activity; smoking

eISSN: 2398-4287@ 2020. The Authors. Published for AMER ABRA cE-Bsby e-International Publishing House, Ltd., UK. This is an open access article under the CC BYNC-ND license (http://creativecommons.org/licenses/by-nc-nd/4.0/). Peer-review under responsibility of AMER (Association of Malaysian Environment-Behaviour Researchers), ABRA (Association of Behavioural Researchers on Asians) and cE-Bs (Centre for Environment-Behaviour Studies), Faculty of Architecture, Planning \& Surveying, Universiti Teknologi MARA, Malaysia.

DOI: https://doi.org/10.21834/ebpj.v5iSI3.2566

\subsection{Introduction}

The urban population is facing the issue of an unhealthy lifestyle and exposure to the risk of non-communicable diseases (NCD). According to the International Physical Activity Questionnaire (IPAQ) survey, 33.55\% of the population was identified as 'inactive' due to the moderate-intensity level of physical activity such as walking (Lim, 2017). In Malaysia, only 40\% of Malaysians adopted a healthy lifestyle by making sports a culture (Bernama, 2016). Physical inactivity can contribute to the unhealthy behaviour of people, especially in increasing the risk of NCD (Ling et al., 2015; Siti Nur Afiqah et al., 2015). Physical inactivity has been identified as the fourth leading risk factor for global mortality (6\% of deaths globally) (WHO, 2010). In Europe, physical inactivity is attributed to 1.6 million deaths (Fisher et al., 2017). Risk factors for NCDs are related to lifestyle, which includes cigarette smoking, hypertension, hyperglycemia, dyslipidemia, obesity, physical inactivity, and poor nutrition (Arena, et al., 2015; Mazlina and Norzalina, 2014). According to Masana et al. (2017), a healthy lifestyle is an essential factor in the prevention of Cardiovascular Disease (CVD). Risk factors such as high blood pressure, diabetes mellitus, and dyslipidemias, including high total cholesterol, can be modified by lifestyle changes. Furthermore, a study in Iran found evidence indicating that adherence to a healthy lifestyle, as compared to unhealthy lifestyle, was associated with decreased risk of all-cause mortality and mortality from CVD in Iranian adults (Akbar et al., 2016).

eISSN: 2398-4287@ 2020. The Authors. Published for AMER ABRA cE-Bsby e-International Publishing House, Ltd., UK. This is an open access article under the CC BYNC-ND license (http://creativecommons.org/licenses/by-nc-nd/4.0/). Peer-review under responsibility of AMER (Association of Malaysian Environment-Behaviour Researchers), ABRA (Association of Behavioural Researchers on Asians) and cE-Bs (Centre for Environment-Behaviour Studies), Faculty of Architecture, Planning \& Surveying, Universiti Teknologi MARA, Malaysia. DOI: https://doi.org/10.21834/ebpj.v5iSI3.2566 
In 2005 , NCD accounted for $60 \%$ of all projected deaths worldwide, i.e., an estimated 35 million people died of NCD (WHO, 2008). In Malaysia, $71 \%$ of death occurrences were due to NCDs, principally cardiovascular diseases (CVD), diabetes, cancers, and chronic respiratory diseases. Malaysia has also recorded $17 \%$ of the risk of premature death from target NCDs (Noncommunicable Diseases Progress Monitor, 2017). Ischaemic heart diseases (one type of CVD) was the principal cause of death in 2016 of 13.2 per cent, followed by pneumonia (12.5\%), cerebrovascular diseases $(6.9 \%)$, transport accidents $(5.4 \%)$ and malignant neoplasm of trachea, bronchus \& lung (2.2\%) (Department of Statistics Malaysia, 2017). Furthermore, from 1996 to 2006, Malaysia saw a dramatic increase in the prevalence of behaviour-linked diseases, including a $43 \%$ increase in hypertension, $88 \%$ increase in diabetes and a $250 \%$ increase in obesity. However, Malaysian society did not seem aware that obesity is a disease. People tend to ignore the obesity problem (Edwards, 2013).

The five major NCDs are heart disease (cardiovascular disease, CVD), stroke, cancer, chronic respiratory diseases and diabetes. Various studies were carried out on human health, including the NCD and healthy lifestyle. The factors of health are including physical activity, diet or nutrition (Gadais et al., 2017), healthy body weight, alcohol intake, and smoking. For instance, a study by Coughlin et al. (2017) was focusing on the efficacy of a healthy lifestyle intervention for adult clinic patients with type 2 diabetes mellitus. The study was monitoring physical activity and tracking food and beverage consumption. Besides, King et al. (2009) used five characteristics of a healthy lifestyle in their research. The five characteristics are the intake of fruits and vegetables, regular exercise, healthy weight, intake of alcohol and not smoking. Differ from King et al. (2009), Haveman-Nies, et al. (2003) and Wang, et al. (2017) use a healthy diet instead of intake of fruit and vegetable. For them, if the researchers only consider the intake of fruit and vegetable, this cannot count as a healthy diet. There is scientific evidence that a healthy diet and adequate physical activity (i.e., $\geq 30$ minutes of moderateintensity physical activity, $\geq 5$ days per week) play an essential role in the prevention of the NCD (WHO, 2008).

However, the study on human health and a healthy lifestyle with the focus on NCD was lacking in Malaysian urban residential areas, especially the public housing area. Usually, public housing areas with a lower price, are equipped with less amount of public facilities that can be used by residents for physical activity, the healthy lifestyle. Thus, a study was carried out at Bangsar, Kuala Lumpur City with the focus on the Sri Pahang Public Housing area. The study aimed to investigate the lifestyle of residents towards the aspect of health and the relationship with their health condition as measured in NCD.

\subsection{Method}

This study was carried out by using the method of the case study. By using a study area as a case, the study was carried out to cover the healthy lifestyles among the residents and the relationship with their health condition with the focus on NCD. For the aspect of healthy lifestyles, the focus is given to the level of physical activity, type of activity during free time, and experience in smoking. For the aspect of health condition, the study was concentrated on the diagnosed illness among residents with focus given to NCD only. The level of physical activities was measured by the frequency and duration of carrying out physical exercise by respondents.

\subsection{Case Study}

Sri Pahang Public Housing (Flat Sri Pahang), is located at Bangsar within the administration boundary of Kuala Lumpur City Hall. It consists of three blocks of apartments with a total of 768 units. The main surrounding land uses are commercial and residential (Fig. 1). The study area is well connected with roads and public transportation networks. It has a direct connection via Jalan Maarof and Jalan Bangsar. For the aspect of the public transport connection, the study area is located adjacent to Bangsar LRT Station.

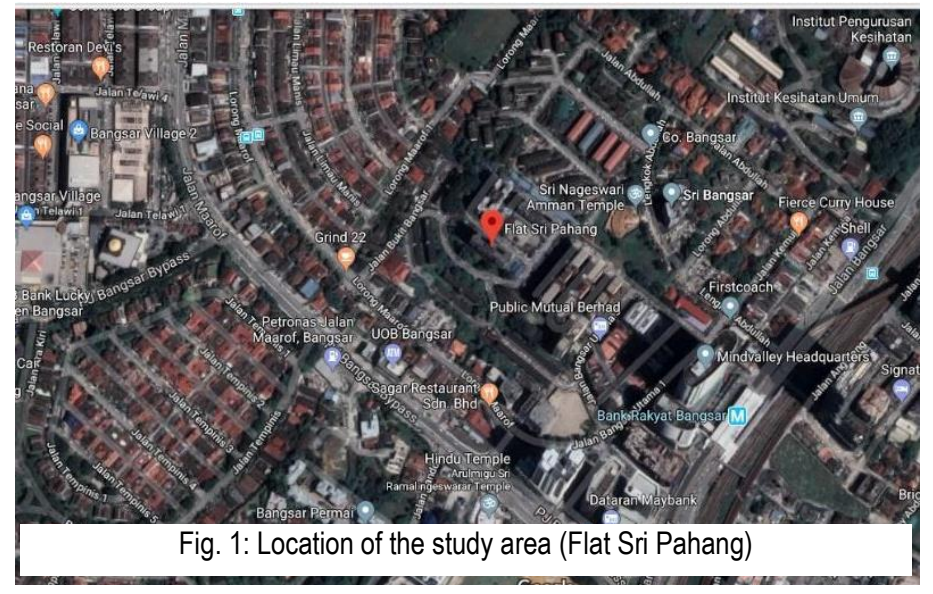

\subsection{Questionnaire Survey and Sampling of Respondents}

The level of physical activity and healthy condition of respondents were identified through a questionnaire survey. A total of 263 respondents were selected from the total population of 3,840 in the study area by using a systematic simple random sampling method. The samples were determined with a confidence level of $95 \%$. The samples covered both male and female, different ethnic groups, 
and different age groups. The samples were equally distributed among the three blocks of building in the study area (Table 1). Table 2 shows the general background of respondents in this study.

\begin{tabular}{|c|c|c|c|}
\hline Block & $\begin{array}{l}\text { Estimated } \\
\text { Population }\end{array}$ & $\begin{array}{l}\text { Sample } \\
\text { size }\end{array}$ & $\%$ \\
\hline 1 & 1,280 & 88 & 33.4 \\
\hline 2 & 1,280 & 88 & 33.4 \\
\hline 3 & 1,280 & 87 & 33.2 \\
\hline Total & 3,840 & 263 & 100.0 \\
\hline \multicolumn{4}{|c|}{ Table 1 Distribution of samples } \\
\hline Variables & & \multirow{2}{*}{\multicolumn{2}{|c|}{ Percentage (\%) }} \\
\hline Gender & & & \\
\hline Male & & & 53.2 \\
\hline Female & & & 46.8 \\
\hline \multicolumn{4}{|l|}{ Ethnicity } \\
\hline Malay & & & 80.6 \\
\hline Indian & & & 14.4 \\
\hline Chinese & & & 4.6 \\
\hline Others & & & 0.4 \\
\hline \multicolumn{4}{|l|}{ Age } \\
\hline$<20$ years old & & & 22.8 \\
\hline $20-29$ years old & & & 22.1 \\
\hline 30-39 years old & & & 18.6 \\
\hline $40-49$ years old & & & 14.8 \\
\hline $50-59$ years old & & & 12.5 \\
\hline$>59$ years old & & & 9.9 \\
\hline
\end{tabular}

\subsection{Method of Analysis}

The data were analysed using the Frequency, Cross-tabulation and Correlation tests in the Statistical Package for Social Science (SPSS) software. The purpose of the analysis is to find out the level of physical activity among residents in the study area and the relationship with the healthy condition (NCD).

\subsection{Results and Discussion}

\subsection{Healthy Lifestyles}

From the questionnaire survey, it was found that the majority of respondents were less active (Table 3). Around $50 \%$ of the respondents did not carry out their exercise regularly. There were only $7.6 \%$ of respondents carrying out exercises more than three times in a week. Most of the respondents were spending their free time by using the internet and watching TV, especially for those who were less frequent in carrying out their exercise (Table 4). It indicates a scenario of a physically inactive and less healthy lifestyle among respondents in the study area. However, the duration of each session of the exercise was considered adequate with more than 30 minutes for most of the respondents ( $>60 \%$ ). Only $37.6 \%$ of respondents carry out their exercise in less than 30 minutes (Table 5).

Another aspect of a healthy lifestyle is the smoking experience of respondents. Only $45.2 \%$ of respondents can be grouped as a non-smoker. There were around $27 \%$ active smokers, $25 \%$ passive smokers and $3 \%$ ex-smoker (Table 6).

Table 3: Frequency of exercise

\begin{tabular}{|c|c|c|}
\hline Per week & $\begin{array}{ll}\text { Number } & \text { of } \\
\text { respondents }\end{array}$ & Percentage (\%) \\
\hline Not regular & 135 & 51.3 \\
\hline 1 & 44 & 16.7 \\
\hline 2 & 36 & 13.7 \\
\hline 3 & 28 & 10.6 \\
\hline$>3$ & 20 & 7.6 \\
\hline Total & 263 & 100.00 \\
\hline
\end{tabular}


Table 4: Frequency of exercise and types of most frequent free time activity

\begin{tabular}{|c|c|c|c|c|c|}
\hline \multirow{2}{*}{$\begin{array}{l}\text { Frequency per } \\
\text { week }\end{array}$} & \multicolumn{5}{|c|}{ Most frequent activity during free time (\% of respondents) } \\
\hline & $\begin{array}{l}\text { Food } \\
\text { stalls I } \\
\text { restaurant }\end{array}$ & $\begin{array}{l}\text { Watching TV } \\
\text { / internet }\end{array}$ & Exercise & Others & Total \\
\hline Not regular & 17.7 & 58.6 & 1.5 & 22.2 & 100.0 \\
\hline 1 & 13.8 & 59.0 & 15.9 & 11.3 & 100.0 \\
\hline 2 & 8.4 & 61.1 & 25.0 & 5.5 & 100.0 \\
\hline 3 & 7.2 & 50.0 & 32.1 & 10.7 & 100.0 \\
\hline$>3$ & 0.0 & 48.0 & 52.0 & 0.0 & 100.0 \\
\hline
\end{tabular}

\begin{tabular}{lcc}
\multicolumn{3}{c}{ Table 5: Duration of exercise } \\
\hline Venue & Frequency & $\%$ \\
$<0.5 \mathrm{hr}$ & 99 & 37.6 \\
$0.5-1 \mathrm{hr}$ & 102 & 38.8 \\
$1-2 \mathrm{hr}$ & 48 & 18.3 \\
$>2 \mathrm{hr}$ & 14 & 5.3 \\
Total & 263 & 100.0 \\
\hline \multicolumn{3}{c}{} \\
& Table 6: Smoking experience \\
\hline \multirow{3}{*}{ Active smoker } & Number of respondents & Percentage (\%) \\
Passive smoker & 70 & 26.6 \\
Ex-smoker & 66 & 25.1 \\
Non-smoker & 8 & 3.0 \\
Total & 119 & 45.2 \\
\hline
\end{tabular}

\subsection{Healthy Lifestyles and NCD}

There were around $40 \%$ of respondents suffering from NCD (Table 7). It showed that there was a high percentage of respondents that can be categorised as unhealthy. It is in line with the level of physically inactive and other unhealthy lifestyles. Based on Table 3 , there were $51.3 \%$ of respondents who did not regularly carry out physical activity. Furthermore, $37.6 \%$ of respondents did not carry out their physical activity more than 30 minutes per session (Table 5). Besides, only $45.2 \%$ of respondents can be grouped under the category of the non-smoker (Table 6). Most of the respondents were spending their free time using the internet/watching TV or eating at food stalls/restaurants (Table 4).

By comparing the data among respondents with $N C D$ and without $N C D$, it was found that a higher percentage of respondents with NCD did not carry out exercise regularly (Table 8). Also, there was a higher percentage of respondents with NCD carrying out their exercise less than 0.5 hours as compared to the respondents without NCD (Table 9). Besides, Table 10 showed that most of the respondents with NCD were having moderate physical activity, i.e., walking (40.7\%). In contrast, most of the respondents without NCD were having more vigorous physical activity, i.e., jogging and sports (Table 10). It showed that a higher percentage of respondents without NCD (more healthy respondents) were more active physically as compared to those who were less healthy.

Table 7: Non-communicable Diseases (NCD) patients among respondents

\begin{tabular}{lrr}
\hline Health & Frequency & $\%$ \\
High blood pressure & 34 & 12.9 \\
Heart diseases & 8 & 3.0 \\
Obesity & 23 & 8.7 \\
Other NCD & 38 & 14.4 \\
Without NCD & 160 & 60.8 \\
Total & 263 & 100.0 \\
\hline
\end{tabular}

Table 8: NCD and frequency of exercise

Frequency of exercise (\% of respondents)

$\begin{array}{lrrrrrrrrr}\text { Health } & \text { Not regular } & \begin{array}{l}1 \text { per } \\ \text { week }\end{array} & \begin{array}{l}2 \\ \text { week }\end{array} & \text { per } & \begin{array}{l}3 \text { per } \\ \text { week }\end{array} & \begin{array}{l}>3 \\ \text { week }\end{array} & \text { per } & \text { Total } \\ \text { With NCD } & 68.9 & 6.8 & & 6.8 & & 11.6 & & 5.9 & 100.0\end{array}$




\begin{tabular}{|c|c|c|c|c|c|c|}
\hline $\begin{array}{l}\text { Without } \\
\text { NCD }\end{array}$ & 40.0 & 23.1 & 18.1 & 10.0 & 8.8 & 100.0 \\
\hline \multicolumn{7}{|c|}{ Table 9: NCD and duration of exercise } \\
\hline & \multicolumn{6}{|c|}{ Duration of exercise (\% of respondents) } \\
\hline Health & :0.5 hour & $0.5-1$ hour & $1-2$ hour & $>2$ ho & \multicolumn{2}{|l|}{ Total } \\
\hline With NCD & 48.5 & 34.9 & 14.7 & 1.9 & \multicolumn{2}{|l|}{100.0} \\
\hline Without NCD & 30.6 & 41.3 & 20.6 & 7.5 & \multicolumn{2}{|l|}{100.0} \\
\hline \multicolumn{7}{|c|}{ Table 10: NCD and type of exercise } \\
\hline \multicolumn{7}{|c|}{ Type of exercise (\% of respondents) } \\
\hline Health & alking & Jogging & $\mathrm{Sp}$ & & Others & Total \\
\hline With NCD & 40.7 & 14.5 & 4.8 & 20.6 & 19.4 & 100.0 \\
\hline $\begin{array}{l}\text { Without } \\
\text { NCD }\end{array}$ & 18.1 & 33.1 & 6.4 & 33.1 & 9.3 & 100.0 \\
\hline
\end{tabular}

By looking on the issue of obese or overweight, as compared among the four groups of residents based on the BMI, it was found that obese group was having the highest percentage of no regular exercise $(67.3 \%)$. The overweight group follows it with $59.0 \%$ of respondents not regularly carrying their exercise. Those who were normal weight were having the smallest percentage for "no regular exercise" (Table 11). It showed that physically inactive can be associated with overweight and obese problems.

\begin{tabular}{lcccr}
\multicolumn{5}{c}{ Table 11: Frequency of exercise and body mass index (BMI) } \\
\hline $\begin{array}{l}\text { Frequency } \\
\text { week }\end{array}$ & per & Body Mass Index (\% of respondents) & \\
& Underweight (<18.5) & $\begin{array}{c}\text { Normal weight } \\
(18.5-24.9)\end{array}$ & $\begin{array}{c}\text { Overweight } \\
(25.0-29.9)\end{array}$ & Obesity (>30) \\
Not regular & 48.4 & 39.0 & 59.0 & 67.3 \\
1 & 21.2 & 18.0 & 17.8 & 9.6 \\
2 & 27.2 & 17.1 & 10.9 & 1.9 \\
3 & 0.0 & 14.5 & 8.2 & 13.4 \\
$>3$ & 3.0 & 11.4 & 4.1 & 7.6 \\
Total & 100.0 & 100.0 & 100.0 & 100.0 \\
\hline
\end{tabular}

Relationship analysis between the level of physical activity among respondents (frequency and duration of exercise) and their health condition (NCD) had been carried out by using Correlation test. As a result, the analysis showed a positive correlation between the variables and significant at the 0.01 level (Table 12). It showed an increase in frequency and duration of exercise; the respondents are healthier (NCD).

Table 12: Correlation of NCD and frequency and duration of exercise

\begin{tabular}{lcc}
\hline & Frequency of exercise & Duration of exercise \\
Pearson Correlation & $0.168^{* *}$ & $0.196^{* *}$ \\
Sig. (2-tailed) & 0.006 & 0.001 \\
$\mathrm{~N}$ & 263 & 263 \\
\hline \multicolumn{2}{l}{ Note: $^{* *}$ Correlation is significant at the 0.01 level (2-tailed). }
\end{tabular}

\subsection{Conclusion}

To conclude, this study found that most of the respondents were less healthy regarding their lifestyle. Half of them did not carry out their exercise regularly, and around $38 \%$ of respondents did not carry out their exercise more than 30 minutes per session. Majority of respondents were spending their free time by using the internet and watching TV, especially for those who were less frequent in carrying out their exercise. Besides, more than half of the respondents were exposed to cigarette smoking either as active, passive or ex-smokers. The physical inactive among respondents were significantly correlated to their health condition as measured in NCD. Those who were unhealthy were more inactive physically as compared to those who were healthier. In general, there was a high percentage of respondents suffering from NCD. The highest NCD among respondents was high blood pressure. Thus, more effort should be carried out by various parties to improve the level of a healthy lifestyle among residents. Future research can be focused on possible encouragement (programme and environmental design), which can increase the level of a healthy lifestyle, especially physical activity. 


\section{Acknowledgement}

The authors gratefully acknowledge the assistance of Universiti Teknologi MARA (UiTM) in providing the REI research grant (600RMI/DANA 5/3/REI (8/2015)) for making this study and publication successful. The authors are also thankful to all the departments, organisations, and individuals who had contributed to this study.

\section{References}

Akbar, F.M., Marsa, Z., ArashE., et al. (2016). The combined effects of healthy lifestyle behaviors on all-cause mortality: the Golestan cohort study. Arch Iran Med 19 (11): 752-761.

Arena, R, Guazzi, M., Lianov, L., et al. (2015). Healthy lifestyle interventions to combat noncommunicable disease - a novel non hierarchical connectivity model for key stakeholders: a policy statement from the American Heart Association, European Society of Cardiology, European Association for Cardiovascular Prevention and Rehabilitation, and American College of Preventive Medicine. Mayo Clinic Proceedings. 90 (8): 1082-1103.

Bernama (August 2016). Only 40\% of Malaysians practise a healthy lifestyle: Khairy. The Sun Daily. Retrieved from http://www.thesundaily.my/news/1953395.

Coughlin, S.S., Hatzigeorgiou, C., Anglin, J., et al. (2017). Healthy lifestyle intervention for adult clinic patients with type 2 diabetes mellitus. Diabetes Manag (Lond) 7 (2): 197-204

Department of Statistics (2016). Press release: population projection (revised), Malaysia, 2010-2040. DOS Official Web (www.dosm.gov.my).

Edwards, A.(Nov 2013). Obesity a big problem now in Malaysia. The Star. Retrieved from https://www.thestar.com.my/news/nation/2013/11/17/obesity-a-big-problemnow-about-three-million-malaysians-are-obese-says-deputy-minister/

Gadais T, Boulanger M, Trudeau F, Rivard MC (2017). Environments favorable to healthy lifestyles: A systematic review of initiatives in Canada. Journal of Sport and Health Science (2017), doi: 10.1016/j.jshs.2017.09.005

Haveman-Nies A, De Groot CGPM, Van Staveren WA. (2003). Dietary quality, lifestyle factors and healthy ageing in Europe: the SENECS study. British Geriatrics Society. Age and Ageing32: 427-434.

King DE, Mainous AG III, Carnemolla M, Everett CJ (2009). Adherence to Healthy Lifestyle Habits in US Adults, 1988-2006. The American Journal of Medicine (2009) $122,528-534$.

Lim, C.H., (2017), Who is responsible for your health? The Malaysian Insight. Web (https://www.themalaysianinsight.com/s/6970/).

Ling, OHL, Siti Nur Afiqah, MM., Dasimah, O. (2015). Environmental health relation to urban planning and human physical activity. The Malaysian Journal of Analytical Sciences 19 (4): 896-903.

Masana L, Ros E , Sudano I, Angoulvant D. (2017). Is there a role for lifestyle changes incardiovascular prevention? What, when and how? Atherosclerosis Supplements 26 (2017): 2-15.

Mazlina Mansor, Nor Zalina Harun (2014). Health Issues and awareness, and the significant of Green Space for Health Promotion in Malaysia. Procedia Social and Behavioral Sciences 153 (2014) 209-220.

Noncommunicable Diseases Progress Monitor (2017). Geneva: World Health Organization.

Siti Nur Afiqah, MM, Ling, OHL, Dasimah, O., Subramaniam, K. (2015). Theoretical review on environmental health in relation to neighbourhood planning and human physical activity. Procedia - Social and Behavioural Sciences 201: 325-332.

Wang C, Li W, Yin L, Bo J, Peng Y, Wang Y et al. (2017). Comparison of healthy lifestyle behaviors among individuals with and without cardiovascular diseases from urban and rural areas in China: A cross-sectional study. PLoS ONE 12(8): e018981.

WHO (2008). Preventing Noncommunicable Diseases in the Workplace through Diet and Physical Activity. World Health Organisation and World Economic Forum.

WHO (2010). Global recommendations on physical activity for health. World Health Organisation. 